\title{
Chloroquine Embryotoxicity in the Postimplantation Rat Conceptus In Vitro
}

\author{
JEFFREY L. AMBROSO AND CRAIG HARRIS \\ Toxicology Program, Department of Environmental and Industrial Health, \\ University of Michigan, Ann Arbor, Michigan 48109
}

\begin{abstract}
The embryotoxicity of the antimalarial drug chloroquine (CQ) was evaluated in vitro using the rat whole embryo culture system. CQ was found to be embryotoxic and dysmorphogenic when added directly to the culture media containing gestational day (GD) 10 rat conceptuses. Twenty-six-hr exposure to CQ elicited dose-related decreases in embryonic crown-rump length, protein and DNA contents and increases in the incidence of morphologically abnormal embryos. At $30 \mu \mathrm{M} \mathrm{CQ}$, embryonic protein content was decreased to $67 \%$ and DNA content to $58 \%$ of control while the incidence of morphological abnormalities rose to $100 \%$. Abnormal axial rotation, microophthalmia, and selective cephalic hypoplasia were the most common developmental abnormalities observed. Visceral yolk sac (VYS) vasculature and blood pigmentation were also decreased in a dose-dependent manner, as was VYS DNA content ( $80 \%$ of control at $30 \mu \mathrm{M}$ ). VYS protein content, however, showed an alternate pattern of response, decreasing to $87 \%$ of control at $10 \mu \mathrm{M} \mathrm{CQ}$ but increasing to $125 \%$ of control at $30 \mu \mathrm{M}$. Histologic evaluation revealed that the cytoplasm of the VYS endoderm epithelium was distended due to vacuolization produced by CQ exposure. In the embryo proper, CQ inhibited cranial neural tube development and altered the morphology of cranial neural crest cells. These observations document the in vitro embryotoxicity of $\mathrm{CQ}$ and suggest altered VYS histiotrophic nutrition as well as direct embryonic effects as possible mechanisms of CQ embryotoxicity. (c) 1993 Wiley-Liss, Inc.
\end{abstract}

Chloroquine (CQ) has been used for more than forty years as an antimalarial drug and more recently in the treatment of rheumatoid arthritis (RA), systemic lupus erythematosis (SLE) and insulin resistant diabetes mellitus (Mackenzie, '83; Blazar et al., '84). The drug is able to cross the human placenta, having been found in human cord blood (Eissen and Afamefuna, '82). While some authorities recommend $\mathrm{CQ}$ as the drug of choice for malarial prophylaxis during pregnancy (Briggs et al., '90), limited epidemiologic data are not sufficient to exclude the possibility that prophylactic doses of CQ are teratogenic (Wolfe and Cordero, '85). Treatment of SLE and RA with CQ during pregnancy raises more concern regarding the potential for human embryotoxicity. Dosages for these conditions are typically higher than those used in malarial prophylaxis and high dose CQ exposure during pregnancy has been more directly asso- ciated with human birth defects (Hart and Naunton, '64). Levy et al. ('91) also found a higher than normal rate of fetal loss, but no evidence of congenital malformations, among a small sample of women who had been treated with CQ for SLE, RA, or malarial prophylaxis during the first trimester of pregnancy. These authors recommended further studies to better assess the potential risk of $\mathrm{CQ}$ treatment during pregnancy, especially with regard to the possible cumulative effects of $C Q$ administration throughout gestation.

Despite the widespread use of $\mathrm{CQ}$ and reports of human birth defects associated with

\footnotetext{
Received December 7, 1992; accepted April 26, 1993

Address reprint requests to Dr. Craig Harris, Toxicology Program, Department of Environmental and Industrial Health, University of Michigan, 1420 Washington Hts., Ann Arbor, MI 48109-2029.
} 
its usage, few studies have systematically investigated mechanisms of CQ embryotoxicity in animal models. Udalova ('67) found increased resorptions and ocular malformations in rats treated with $C Q$ during early organogenesis. Long-term administration of CQ to pregnant rats has also been reported to be teratogenic, resulting in fetal growth retardation and various malformations including hepatomegaly, liquifaction of the brain and visceral organs and skeletal alterations (Sharma and Rawat, '89). The drug has been found to be embryolethal, teratogenic and capable of synergizing the teratogenicity of cholinomimetic drugs when injected into the yolk sacs of chicken embryos (Landauer, '78). Several studies have demonstrated the ability of CQ to modulate the embryotoxicity of other teratogenic agents. Yeilding et al., ('76) used an unspecified nonteratogenic dose of $C Q$ to enhance the teratogenic effects of $\mathrm{x}$-rays in mice, while Burkard and Fritz-Niggli ('87) found CQ protected mice from the teratogenic and transplacental carcinogenic effects of urethane. In the later study, however, only a single dose of $\mathrm{CQ}$ was given on gestational day 14 , very late in organogenesis.

Ongoing studies, directed at understanding the relationship between chemical disruption of nutritional pathways and dysmorphogenesis, led us to evaluate the in vitro embryotoxicity of $\mathrm{CQ}$ because of its reported effects on cellular vacuolar systems. $\mathrm{A}$ number of studies have found that $\mathrm{CQ}$ and other related amines inhibit lysosomal hydrolases (Lie and Schofield, '73; Basu et al., '81; Nato et al., '82; Kaiser et al. '85; Shimizu and Kawashima, '89) and disrupt the endocytotic uptake and vacuolar sorting of external macromolecules (King et al., ' 80 ; Tietze et al., '80; Posner et al., '82; Merion and Sly, '83). These effects have most often been attributed to increased vacuolar $\mathrm{pH}$ and/or osmotic effects of these compounds, although Wibo and Poole ('81) determined that $\mathrm{CQ}$ could directly and reversibly inhibit cathepsin B1. CQ has also been found to inhibit endocytosis and lysosomal function in cultured GD 17 rat VYSs (Livesay, et al., ' 80 ). We hypothesize that $\mathrm{CQ}$ may be embryotoxic or embryolethal due to an inhibition of the nutritional function of the VYS during organogenesis. This process, known as histiotrophic nutrition, involves endocytosis and lysosomal degradation of maternal proteins by the VYS endoderm ep- ithelium and the subsequent transfer of amino acids to the embryo proper for synthesis of new proteins (Freeman et al., '81; Freeman and Lloyd, '83). Disruption of VYS histiotrophic nutrition as a mechanism of chemical teratogenesis was first proposed by Beck et al., ('67) for the azo dye trypan blue. Since that time, the vital nutritive role played by the rat VYS prior to the establishment of the chorioallantoic placenta has been well documented and a number of chemical agents have been found whose embryotoxicity can be attributed to alterations of VYS histiotrophic nutrition (for review see Beckman et al., '90; Brent et al., '90; Freeman, '90; and Lloyd, '90). Thus, any chemical capable of inhibiting endocytosis and/or lysosomal function can be regarded as a potential in vivo rodent teratogen.

The objective of the current study was to assess the embryotoxicity and dysmorphogenic potential of $\mathrm{CQ}$ in rat whole embryo culture. This system allows us to focus on the conceptus as a direct target without the confounding factors of maternal toxicity and metabolism. To our knowledge the embryotoxicity of $\mathrm{CQ}$ has not previously been investigated in vitro during organogenesis. This report provides data which indicate that low doses of CQ are directly embryotoxic and effect embryonic and VYS morphology in vitro. The implications of these data with respect to the possible mechanisms of $\mathrm{CQ}$ teratogenicity are discussed.

\section{MATERIALS AND METHODS Chemicals}

Chloroquine diphosphate (CQ) was obtained from Sigma Chemical Company (St. Louis, Mo.). All other reagents were purchased from various sources and were of the highest quality commercially available.

\section{Animals}

Time-mated primigravida Sprague-Dawley rats were obtained from the Reproductive Sciences Program Small Animal Core Facility, the University of Michigan, on gestational days 7-9. The morning following copulation, as indicated by a sperm positive vaginal smear, was designated as gestational day zero. Pregnant animals were maintained on a 14-hr light/10-hr dark cycle and given free access to Purina Rat Chow (Ralston Purina) and water until the morning of explantation. 


\section{Embryo culture}

On the morning of GD 10, pregnant dams were anesthetized with ether and their blood collected from the abdominal aorta. The blood was centrifuged, the serum heatinactivated and stored at $-20^{\circ} \mathrm{C}$ for subsequent use in culture media. Uteri were removed from the dams, placed in warmed Hanks balanced salt solution (HBSS, Gibco BRL, Gaithersburg, MD) and the implantation sites dissected free. Conceptuses were carefully removed from the decidual mass and Reichert's membrane was opened to allow the embryo to develop properly in culture. Conceptuses were placed in $125 \mathrm{ml}$ roller bottles containing $33 \%$ heat-inactivated female rat serum in HBSS supplemented with penicillin $\mathrm{G}(100 \mathrm{IU} / \mathrm{ml})$ and streptomycin $(50 \mu \mathrm{g} / \mathrm{ml})$. The media had been warmed to $37^{\circ} \mathrm{C}$ and gassed with $20 \%$ $\mathrm{O}_{2} / 5 \% \mathrm{CO}_{2} / 75 \% \mathrm{~N}_{2}$ prior to addition of conceptuses. Less than ten conceptuses per bottle were cultured in a total volume of $15 \mathrm{ml}$ culture media. The bottles were sealed and placed in a roller incubator overnight, then regassed with $95 \% \mathrm{O}_{2} / 5 \% \mathrm{CO}_{2}$ on the morning of GD 11. Morphological assessments took place at 1 PM on GD 11 after approximately $26 \mathrm{hr}$ of culture.

\section{Exposure}

Stock CQ solutions of $15 \mathrm{mg} / \mathrm{ml}$ were prepared fresh in sterile HBSS, $\mathrm{pH}$ 7.4. The stock or vehicle was added directly to the culture media just prior to addition of conceptuses on the morning of GD 10, and exposure was continuous throughout the culture period.

\section{Assessment}

Following $26 \mathrm{hr}$ in culture, conceptuses were removed from their culture bottles, rinsed with warm HBSS, and placed in dishes containing warm HBSS for assessment of viability (heartbeat and yolk sac circulation) and malformations. Assessments were performed using a Wild M8 dissecting microscope and conducted blind in order to minimize bias. Nonviable conceptuses were excluded from biochemical and histological analysis. Yolk sac morphology was scored numerically according to the criteria of Seegmiller et al. ('91), with 0 denoting a healthy VYS (extensive vitelline vasculature containing numerous pigmented blood cells and steady circulation) and
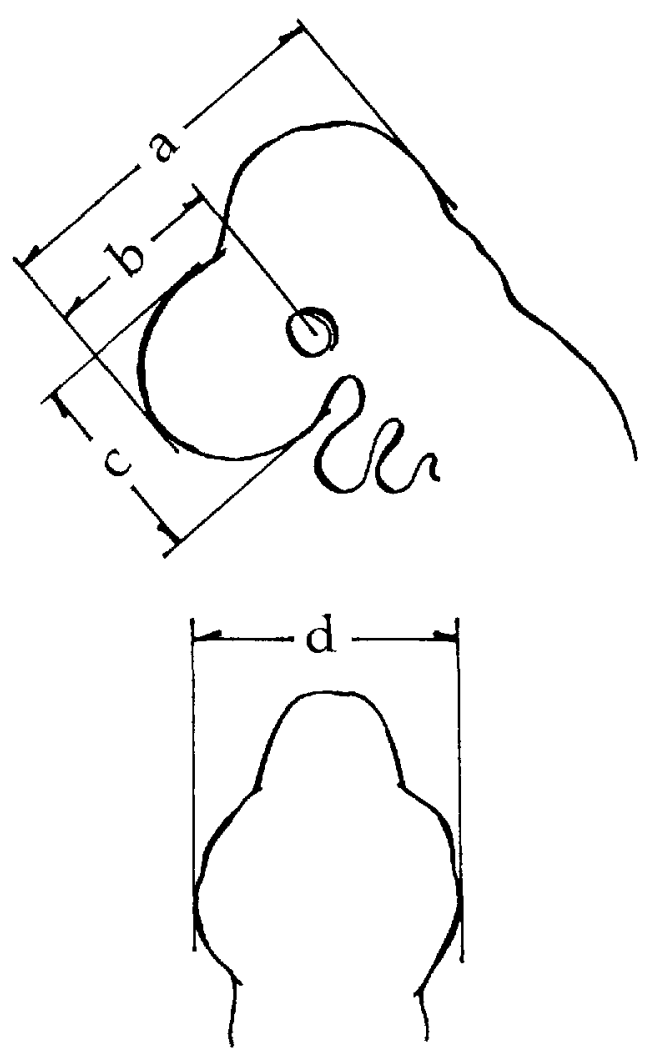

Fig. 1. Diagram of Embryonic Head measurements. a: Total head length-distance from the dorsal hindbrain to the rostral forebrain when viewed from the side. b: Prosencephalon length-distance from the optic cup midline to the rostral forebrain when viewed from the side. c: Prosencephalon height-distance from the caudal forebrain near the primitive mouth to the forebrain-midbrain junction. d: Total head width-distance between the widest points of the head when viewed from behind. This area is the lateral hindbrain region.

scores of 1-4 to VYS abnormalities of increasing severity (denoting diminished pigment, vasculature and circulation). A score of 4 indicates an avascular yolk sac without visible blood pigment or circulation. Yolk sacs were removed by dissection and measurements taken of crown-rump length and head size (Fig. 1) with the aid of an ocular micrometer. Embryos with frank alterations in axial rotation were excluded from the crown-rump measurements. The embryos were evaluated for neural tube closure, axial rotation and morphologic abnormalities. The embryos and yolk sacs were then placed separately in $1 \mathrm{ml}$ of ice-cold sodium phosphate buffer ( $50 \mathrm{mM}, \mathrm{pH} 6.0$ ) 
TABLE 1. Chloroquine morphology study data

\begin{tabular}{|c|c|c|c|c|}
\hline $\begin{array}{l}\text { Initial } \\
\text { chloroquine } \\
\text { concn }\end{array}$ & \% Viability ${ }^{1}$ & \% Dysmorphic ${ }^{2}$ & $\begin{array}{c}\text { Crown-rump } \\
(\mathrm{mm})\end{array}$ & Yolk sac score $^{3}$ \\
\hline 0 (Control) & $100(47 / 47)$ & $4(2 / 47)$ & $3.4 \pm 0.2$ & $0.0 \pm 0.0$ \\
\hline $10 \mu \mathrm{M}$ & $100(33 / 33)$ & $24(8 / 33)^{\dagger}$ & $3.3 \pm 0.2$ & $0.2 \pm 0.4$ \\
\hline $20 \mu \mathrm{M}$ & $100(35 / 35)$ & $63(22 / 35)^{\dagger}$ & $3.2 \pm 0.2^{*}$ & $1.4 \pm 0.8^{\dagger}$ \\
\hline $30 \mu \mathrm{M}$ & $88(36 / 41)$ & $100(36 / 36)^{\dagger}$ & $2.9 \pm 0.2^{* *}$ & $2.6 \pm 0.7^{+}$ \\
\hline
\end{tabular}

${ }^{1}$ Number of conceptuses possessing active heartbeat and yolk sac circulation at the end of the culture period/number cultured. Combined data from six experiments.

${ }^{2}$ Number of morphologically abnormal embryos at the end of the culture period/number cultured. Morphologic abnormalities consisted of any of the following singly or in combination; abnormal axial rotation, prosencephalic hypoplasia, mesencephalic hypoplasia, anopthalmia, microopthalmia, craniofacial blisters, lateral protrusions in the hindbrain, cloacal extrophy.

Mean \pm SD.

* Significantly different than control by Scheffe test, $P<0.05$.

** Significantly different than control by Scheffe test, $P<0.001$

'Significant at $P<0.05$ by Chi-square.

TABLE 2. Embryonic head measurements ${ }^{1}$

\begin{tabular}{llccc}
\hline $\begin{array}{l}\text { Chloroquine } \\
\text { concn }\end{array}$ & $\begin{array}{c}\text { Total head } \\
\text { length }\end{array}$ & $\begin{array}{c}\text { Prosencephelon } \\
\text { length }\end{array}$ & $\begin{array}{c}\text { Prosencephelon } \\
\text { height }\end{array}$ & $\begin{array}{c}\text { Total head } \\
\text { width }\end{array}$ \\
\hline 0 (Control) & $1.7 \pm 0.1(42)$ & $0.6 \pm 0.1(42)$ & $0.8 \pm 0.1(26)$ & $1.3 \pm 0.1(41)$ \\
$10 \mu \mathrm{M}$ & $1.7 \pm 0.1(33)$ & $0.5 \pm 0.1(33)^{* *}$ & $0.8 \pm 0.1(27)$ & $1.3 \pm 0.1(26)$ \\
$20 \mu \mathrm{M}$ & $1.5 \pm 0.2(32)^{* *}$ & $0.4 \pm 0.1(32)^{* *}$ & $0.7 \pm 0.1(25)^{* *}$ & $1.3 \pm 0.1(25)$ \\
$30 \mu \mathrm{M}$ & $1.3 \pm 0.1(36)^{* *}$ & $0.4 \pm 0.1(29)^{* * *}$ & $0.6 \pm 0.1(22)^{* *}$ & $1.3 \pm 0.1(30)$ \\
\hline
\end{tabular}

${ }^{1}$ Measurements were as described in Materials and Methods (see Fig. 1). Data are means \pm SD of pooled samples (n) from six replicate experiments. All categories except total head width showed significant overall differences between treatments by one-way ANOVA. ** Significantly different than control, $P<0.001$ by Scheffe multiple comparison test.

containing $1 \mathrm{mM}$ ethylenediaminetetraacetic acid (EDTA), ultrasonically disrupted, and frozen at $-70^{\circ} \mathrm{C}$ for subsequent protein and DNA determinations.

\section{Protein and DNA assays}

Protein content was determined by the method of Bradford (76) using bovine gamma globulin standard and dye reagent supplied by BioRad (Richmond, Ca.). The assay was modified for microtiter plate assay as described by Stark et al. ('87). DNA content was determined by the method of Labarca and Paigen ('80) using bovine DNA as a standard.

\section{Histology}

Representative samples of control and CQ-treated conceptuses were prepared with the assistance of the University of Michigan Reproductive Sciences Program Morphology Core. Briefly, GD 11.5 embryos and yolk sacs were separated, rinsed in ice-cold $0.9 \%$ $\mathrm{NaCl}$, and placed in Karnovsky's fixative. The fixed tissues were later dehydrated in a graded ethanol series, embedded in glycol methacrylate polymer, and cut in $3-5-\mu \mathrm{m}$ transverse sections. Every fifth section was saved and stained with hematoxylin and eosin (H\&E). Examination and photography of the sections was performed by the authors at the University of Michigan Cell Biology Laboratories using a Leitz Orthoplan microscope with a Wild camera attachment.

\section{Statistical analysis}

The chi-square test was used to determine differences in discrete data (malformation rate and yolk sac score). The statistical software package Statview (Abacus Concepts, Inc. 1986) was used to analyze continuous data. One-way analysis of variance (ANOVA) was used to determine overall differences between treatment groups. This was followed by the Scheffe test for multiple comparison of individual treatment means $(P<0.05$ were considered significant $)$.

\section{RESULTS}

Dose-response experiments $(0-50 \mu \mathrm{M})$ indicated that CQ was embryotoxic and dysmorphogenic when present in the culture media of gestational day $10-11$ conceptuses grown in vitro. Addition of $\mathrm{CQ}$ to the culture media at concentrations greater than $50 \mu \mathrm{M}$ produced $100 \%$ embryolethality when evaluated on day 11. CQ concentrations of $10-30 \mu \mathrm{M}$ were chosen for our studies since 


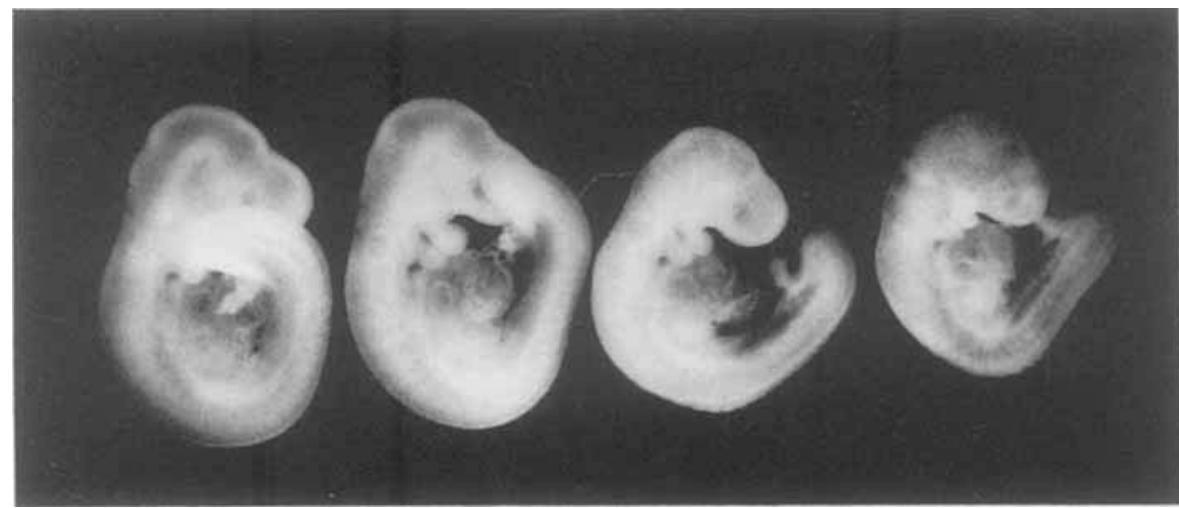

Fig. 2. Morphology of GD 11.5 embryos at the end of the 26-hr culture period Control (left), and embryos exposed to increasing concentrations of chloroquine in the culture media $(10,20$, and $30 \mu \mathrm{M}$ from left to right). Note the dose-related increase in abnormal axial rota-

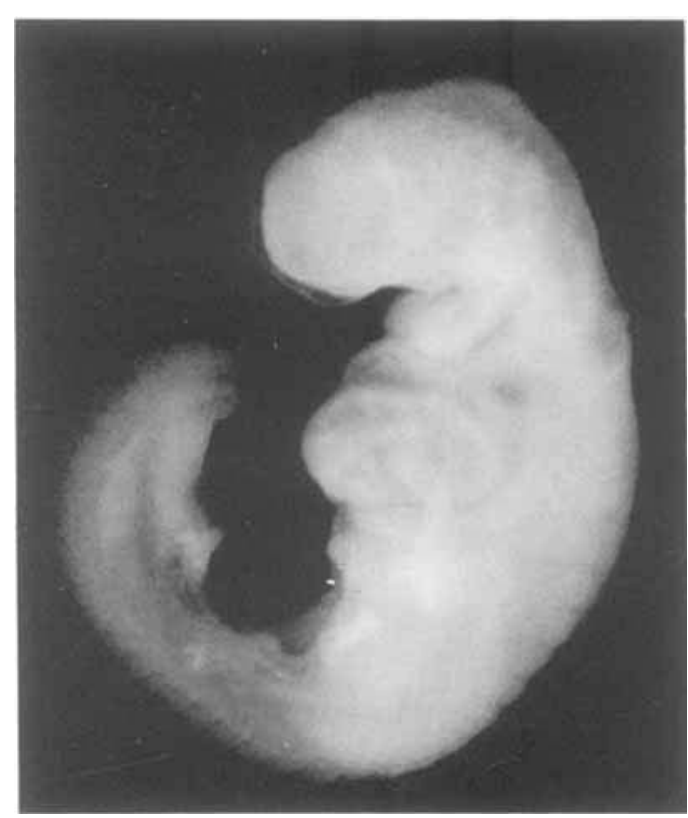

Fig. 3. GD 11.5 embryo exposed to $30 \mu \mathrm{M} \mathrm{CQ}$ in the culture media for $26 \mathrm{hr}$. Note abnormal axial rotation, anopthalmia, blistering in the prosencephalon and lack of cranial neural tube development. This is an example of the more severe effects observed at this concentration of CQ. $\times 37$.

these concentrations were found to elicit dysmorphogenesis in vitro while retaining viability above $85 \%$.

Table 1 shows that CQ concentrations in the range of $10-30 \mu \mathrm{M}$ caused significant tion and hypoplasia in the cephalic region. Microopthalmia is evident in the embryo exposed to $30 \mu \mathrm{M}$ $\mathrm{CQ}$. The extraembryonic tissues have been removed for photography. $\times 11$.

dose-dependent increases in VYS score (0.2-2.8) and incidence of abnormal development (25-100\%); and decreases in embryonic crown-rump length $(3.4-2.9 \mathrm{~mm})$. CQ significantly reduced VYS vascularization and blood pigmentation as evidenced by the increased VYS score $(P<0.05)$. Although all the embryos exposed to $30 \mu \mathrm{M}$ CQ possessed an active heartbeat, several were classified as nonviable due to a lack of VYS circulation. Both the VYS and amnion of treated conceptuses became opaque at the higher CQ concentrations. The most common morphologic abnormalities observed following CQ treatment were craniofacial dysplasia, micropthalmia and abnormal axial rotation. CQ-induced craniofacial dysplasia consisted of hypoplasia of the prosencephalon and protrusions in the lateral region of the hindbrain, in an area just rostral to the 1st branchial arch. These morphologic observations were confirmed by embryonic head measurements (Table 2), which showed a significant dose-related decrease in total head length and prosencephalon size in CQ exposed embryos, while total head width did not differ significantly from the control in any of the treated groups. As the incidence of morphologic abnormalities increased, so did the severity of the dysmorphogenesis observed (Fig. 2). At $10 \mu \mathrm{M} \mathrm{CQ}$, relatively few structural malformations were observed and their severity was limited. At $30 \mu \mathrm{M}$, however, CQ was found to be $100 \%$ dysmorphogenic in the surviving conceptuses. The most severely affected embryos showed 


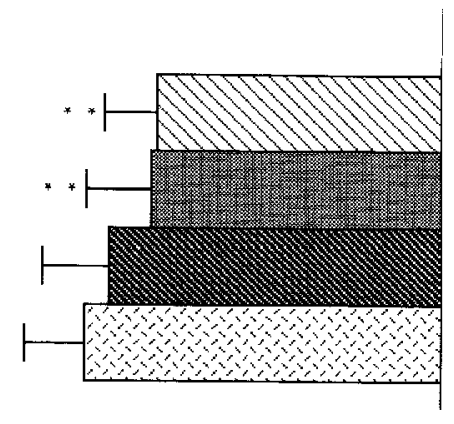

m

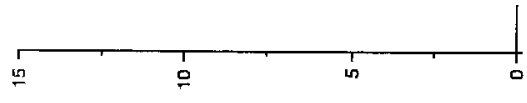

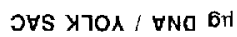

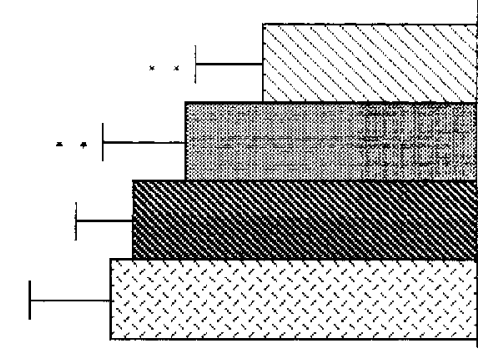

4

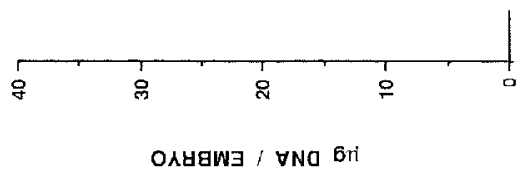

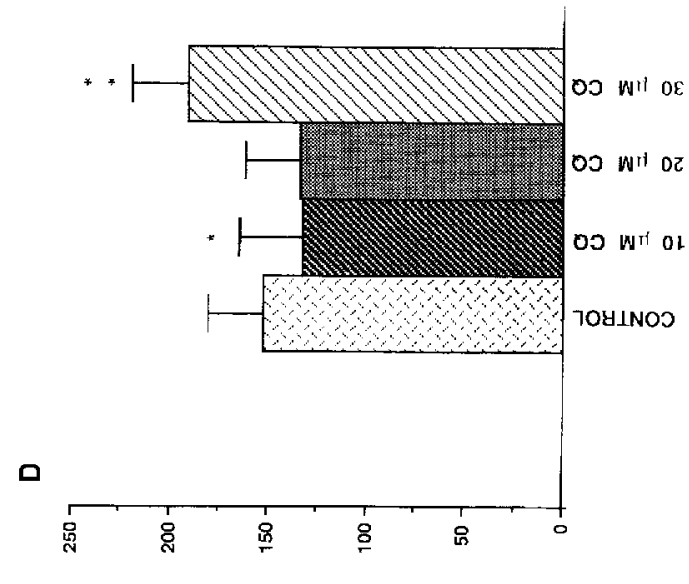

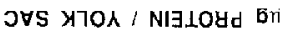

ن্

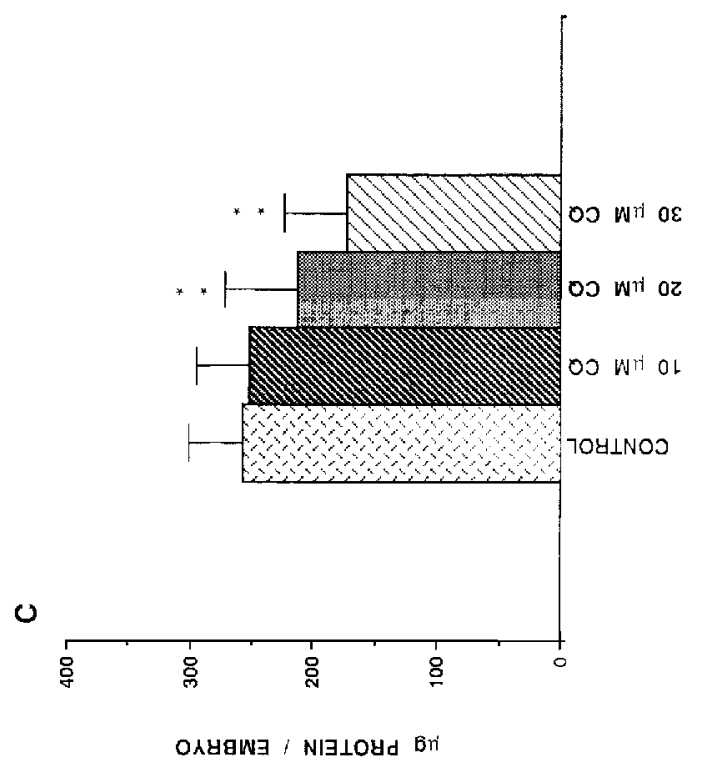


marked inhibition of axial rotation, anopthalmia, craniofacial blisters and necrosis in the trunk region (Fig. 3).

Biochemical growth parameters are presented in Figure 4. CQ treatment resulted in dose-dependent decreases in both protein $(67 \%$ of control at the highest dose, $P<0.001$ ) and DNA content (58\% of control at the highest dose, $P<0.001$ ) in the embryo proper. In the VYS, however, a similar pattern is only evident for DNA content (decreased to $80 \%$ of control with $30 \mu \mathrm{M} \mathrm{CQ}$, $P<0.001$ ). Compared to control, VYS protein content was significantly decreased in the $10 \mu \mathrm{M}$ group ( $87 \%$ of control, $P<0.05$ ), not significantly altered in the $20 \mu \mathrm{M}$ group and significantly increased in the $30 \mu \mathrm{M}$ treatment group (125\% of control, $P<0.001$ ).

The most striking histologic changes resulting from $\mathrm{CQ}$ exposure were observed in the VYS, where the endoderm epithelium displayed a dose-dependent cytoplasmic vacuolization. Thirty $\mu \mathrm{M} \mathrm{CQ}$ ellicited extreme vacuolar swelling which distended the cytoplasm of these cells (Fig. 5). The swollen vacuoles were observed to contain eosinophilic material when stained with hematoxylin and eosin, and are believed to represent the site of protein accumulation in the VYS of conceptuses exposed to $30 \mu \mathrm{M}$ $\mathrm{CQ}$. Vacuolization also occurred in the 10 and $20 \mu \mathrm{M}$ treatment groups (not shown) but was less severe than that seen in the 30 $\mu \mathrm{M}$ group.

Transverse sections through the head region of representative control and $30 \mu \mathrm{M}$ treated embryos are shown in Figure 6 . It is apparent that $\mathrm{CQ}$ delayed cranial neural tube development including the development of the optic cup. While the neural epithelium of the CQ-treated embryo appears to posess normal morphology, its thickness appears reduced, especially in the hindbrain (control neuroepithelium contained an average of five cell nuclei while the $30 \mu \mathrm{M}$ treated embryo had four). In addition, the

Fig. 4. DNA and protein contents of GD $11.5 \mathrm{em}-$ bryos (A,C) and visceral yolk sacs (B,D) at the end of the 26-hr culture period. Note the differential pattern of response between the embryo and VYS protein contents. Bars represent means $+\mathrm{SD}$ from $\mathrm{n}=42$ (Control); $33(10 \mu \mathrm{M}) ; 32(20 \mu \mathrm{M})$; and $36(30 \mu \mathrm{M})$ samples from six replicate experiments. *Significantly different than control, $P<0.05$ by Scheffe multiple comparison test. **Significantly different than control, $P<0.001$ by Scheffe multiple comparison test. brain vesicles had not developed to the same extent as seen in the control. The forebrain of the control embryo had expanded and begun to develop into the telencephalon while the forebrain of the treated embryo was not expanded, and remained in a state resembling a late GD 10 rather than GD 11 forebrain. This lack of cephalic neural tube expansion, together with decreased mesen chymal extracellular space, results in marked hypoplasia in the cephalic region in general. An exception to generalized hypoplasia was observed in the lateral hindbrain region, where the primordia of the fifth cranial nerve is formed from neural crest cell derivatives. In the CQ-treated embryo, the mesenchyme in these areas contains aggregations of cells with a charac teristic rounded morphology. The lateral protrusions observed externally in this region appear to result from these cell aggregates. These cells in the CQ-treated embryo correspond to the primordia of the fifth cranial nerve seen in the control section, although their location appears to be displaced slightly ventral with respect to the anterior cardinal vein. Higher magnification of these cells (Figs, 7, 8) reveals cytoplasmic vacuolization and a rounded morphology that was not evident in the corresponding control cells. It is also clear from these micrographs that the extracellular space surrounding much of the mesenchyme (especially near the forebrain) is reduced in the CQ-treated embryo.

\section{DISCUSSION}

The current study partially characterizes the in vitro embryotoxicity of $\mathrm{CQ}$ in rats. Relatively low concentrations of $\mathrm{CQ}$ cause growth retardation, dysmorphogenesis and embryolethality when added directly to the culture media of day $10-11$ rat conceptuses grown in vitro. Since $\mathrm{CQ}$ has been found to cross the placenta and accumulate in fetal tissues of mice (Ullberg et al., '70), our data imply that the in vivo rodent teratogenicity of $\mathrm{CQ}$ may be due to direct effects of the drug on the organogenesis stage conceptus, rather than to maternal toxicity alone.

$\mathrm{CQ}$ appears to preferentially affect rapidly developing tissues in the conceptus. In the VYS, CQ treatment dramatically reduced vascularization and blood pigmentation. An interesting, yet untested hypothesis, is that increases in vacuolar $\mathrm{pH}$ induced by $\mathrm{CQ}$ may inhibit the intracellular release 

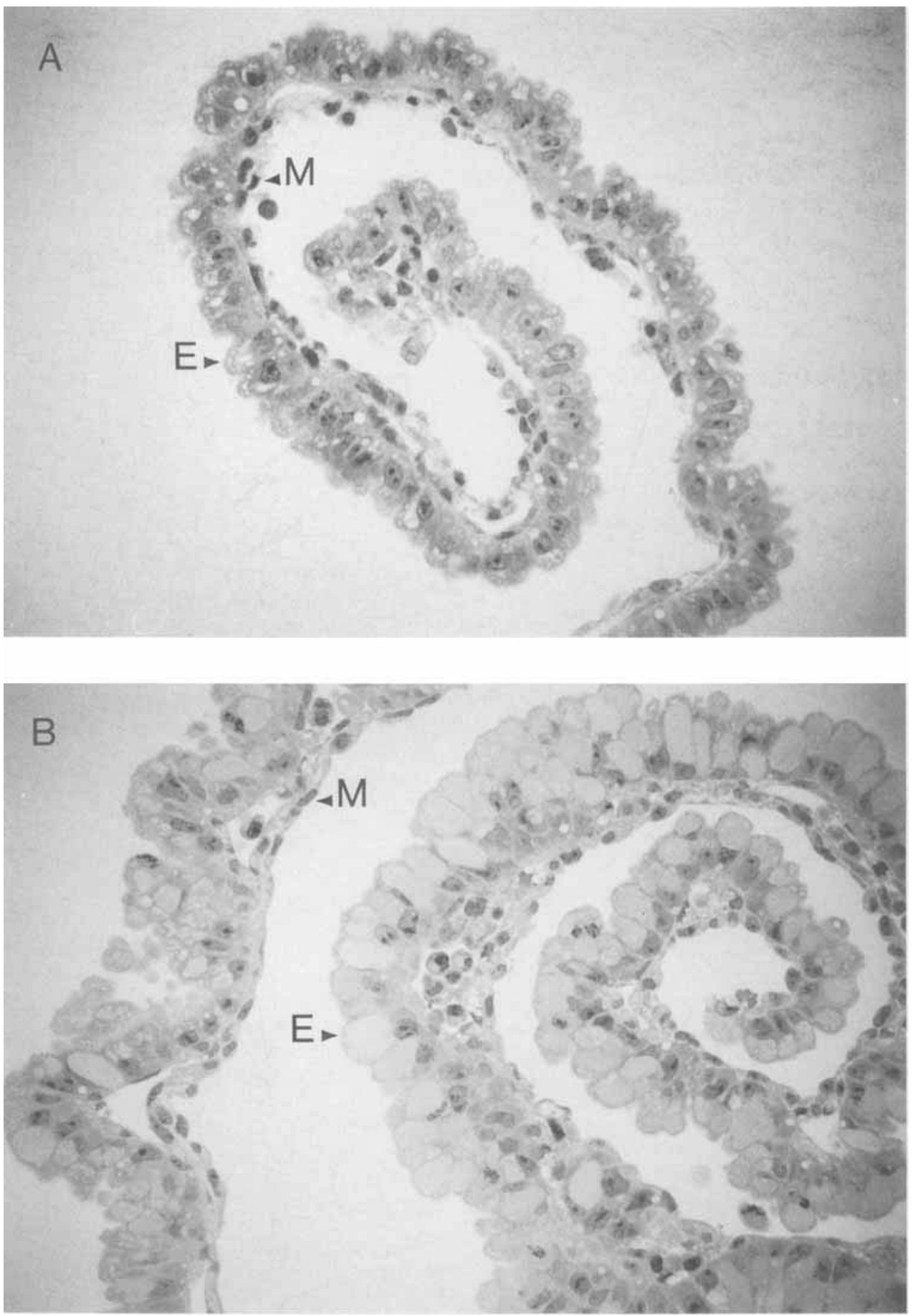

Fig. 5. Histologic appearance of GD 11.5 control (A) and $30 \mu \mathrm{M}$ CQ-treated (B) VYSs. The basic VYS architecture is not altered by CQ treatment; the endoderm epithelium (E) is supported by a thin mesothelium (M), and contains vitelline vessels. The control endoderm cells contain numerous absorptive vacuoles that do not stain with H\&E. Note the enlarged vacuoles in the CQ- treated VYS endoderm that distend the cytoplasm of these cells. These vacuoles contain eosinophilic material when stained with $H \& E$ and represent the presumptive site of increased protein content in the $30 \mu \mathrm{M}$ CQ-treated VYSs. $\times 300$, both micrographs (compare nuclear size). 

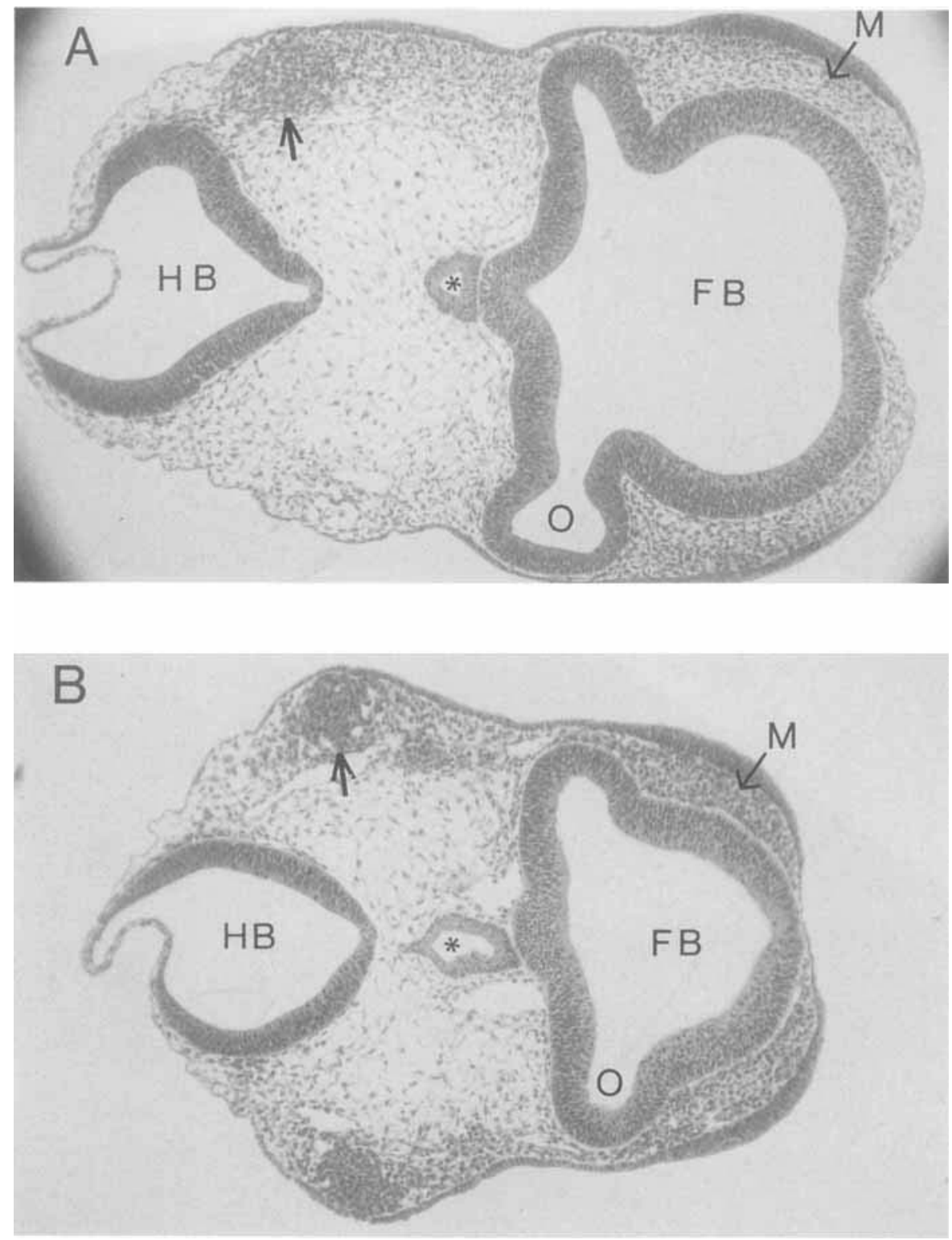

Fig. 6. Cephalic transverse sections taken through the lower optic cup region of control (A) and $30 \mu \mathrm{M}$ CQ-treated (B) embryos at the end of the culture period, stained with H\&E. Rathke's pouch (asterisk) is used as a landmark to compare sections. The control section is cut slightly oblique and therefore appears asymmetric. The control shows an expanded forebrain (FB), welldeveloped optic vesicles $(O)$ and elongated cranial neural crest derivatives (arrow). The forebrain of the $\mathrm{CQ}$ treated embryo has not expanded and the optic vesicles are rudimentary compared to control. The clumps of cells lateral to the anterior cardinal vein in the $\mathrm{CQ}$ treated section (arrow) correspond to the cranial neural crest in the control section. These cells appear condensed, have a rounded morphology and apparently cause the lateral protrusions observed in the hindbrain region of $\mathrm{CQ}$-treated embryos. The mesenchyme $(\mathrm{M})$ of the CQ-treated embryo also exhibits reduced extracellular space compared to the control. HB, hindbrain. $\times 70$, both micrographs. 

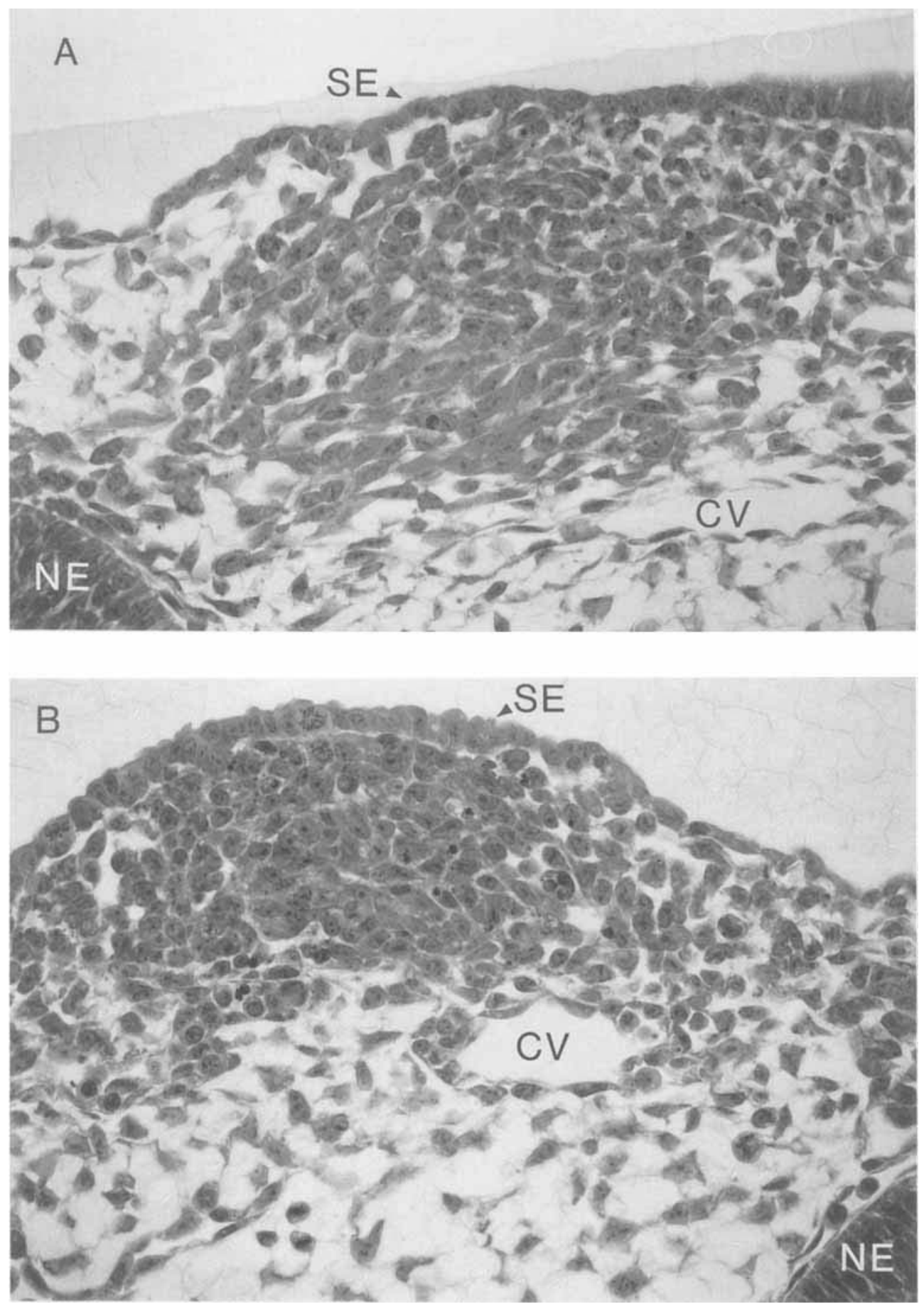

Fig. 7. Higher magnification of areas lateral to the anterior cardinal vein in Fig. 6. This figure shows comparative regions from opposite sides of control (A) and $30 \mu \mathrm{M} C Q$-treated (B) embryos. The area between the anterior cardinal vein (CV) and the surface ectoderm (SE) contains presumptive cranial neural crest derivatives (primordia of the fifth cranial nerve). Many control cells appear elongated and are separated by extracellular spaces. The crest cells in the CQ-treated section appear slightly displaced ventrally, display a rounded morphology, and appear clumped with little extracellular space. NE, hindbrain neural epithelium. $\times 410$, both micrographs. 

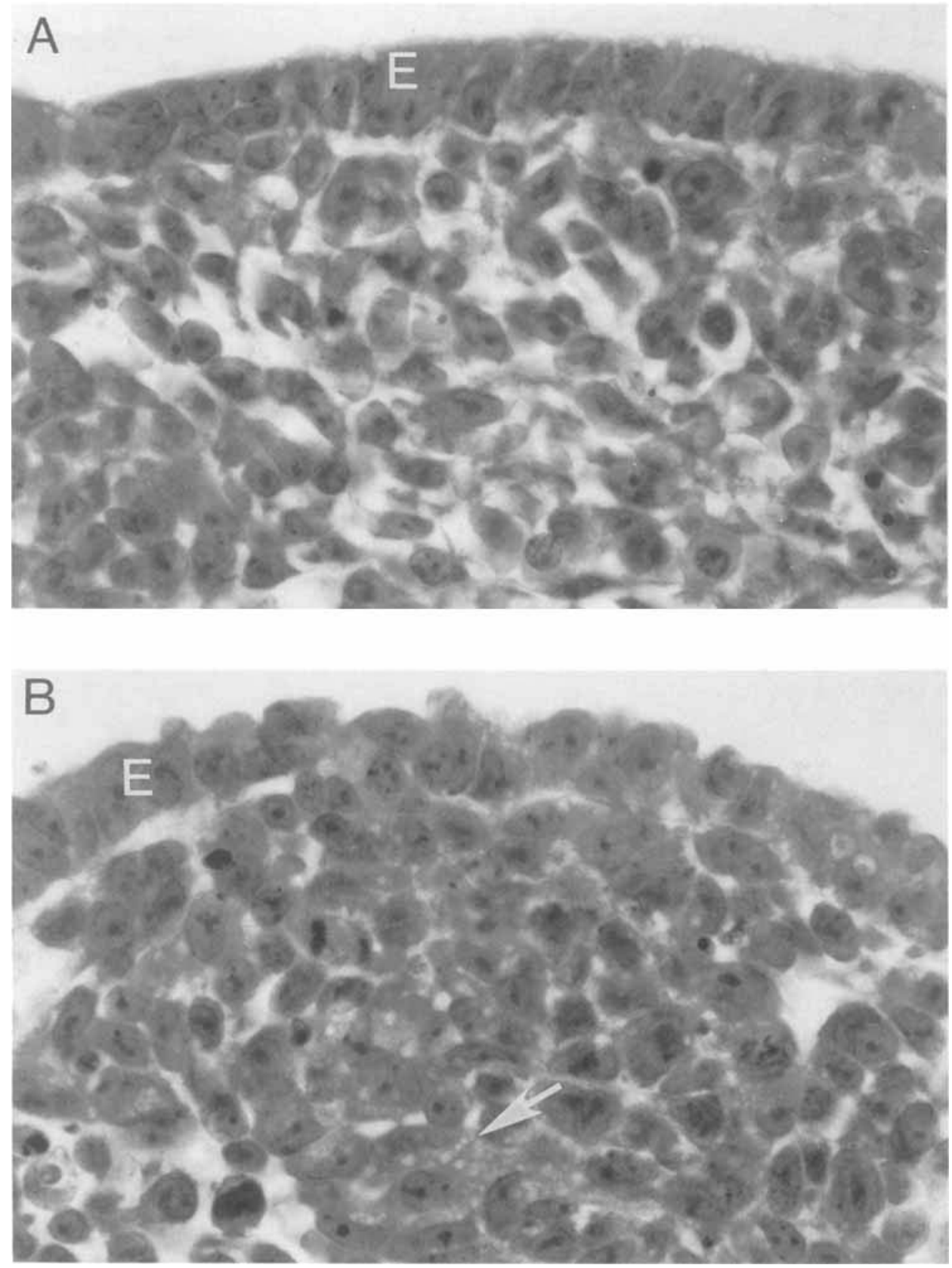

Fig. 8. Presumptive cranial neural crest derivatives from the lateral hindbrain region of control (A) and 30 $\mu \mathrm{M} C Q$-treated (B) embryos. The control cells show uniform areas of extracellular space surrounding cells with a mesenchymal morphology. The $\mathrm{CQ}$-treated cells exhibit vacuolated cytoplasm (arrow) and reduced extracellular space. $\times 450$, both micrographs. E, surface ectoderm. 
of transferrin-bound iron and subsequently decrease the rapid hemoglobin synthesis occurring in the VYS during organogenesis. The intracellular release of iron from receptor-bound transferrin is dependent upon the normally acidic $\mathrm{pH}$ of endosomes (for review see Mellman et al., '86; Wall and Maack, '85). Since CQ treatment has been found to rapidly increase vacuolar $\mathrm{pH}$ (Okhuma and Poole, 78) and inhibit iron release from transferrin in cultured fibroblasts (Octave et al., '82), it seems plausible that conceptuses cultured in the prescence of $\mathrm{CQ}$ may be unable to acquire enough iron to support VYS hematopoiesis. In the embryo proper, craniofacial development and axial development were most affected by conceptal exposure to CQ. Brain, optic and axial development are also three of the most sensitive targets for in vivo teratogenic insult at this gestational age (Wilson, '73). Although the heart is also a sensitive in vivo target at this time, it appeared relatively resistant to $C Q$ treatment in vitro.

Direct exposure to $\mathrm{CQ}$ in the culture media caused dose-related decreases in most of the conceptal growth parameters examined in this study. Notable exceptions were VYS protein content (decreased at $10 \mu \mathrm{M}$ but increased at $30 \mu \mathrm{M}$ ) and total head width (unchanged). These anomalies provide clues as to the possible mechanisms of CQ embryotoxicity. Regarding the former, the biochemical growth parameters presented in Figure 4 clearly show a differential pattern of response in the embryo versus the VYS. While embryonic DNA and protein both decrease with increasing $\mathrm{CQ}$ concentrations, VYS protein content increases at the highest dose even though the DNA content of the same tissues was significantly decreased. These data, together with the histologic findings of enlarged cytoplasmic vacuoles containing eosinophilic material in the endoderm of CQ-treated VYSs, suggest that the drug might inhibit VYS lysosomal proteolysis and therefore histiotrophic nutrition. Although further experimentation is required to validate this hypothesis, it is consistent with the known inhibitory effects of CQ on lysosomal proteolysis in mammalian cells (de Duve et al., '74; Livesay et al., '80; Libby et al., '80; Nato et al., '82; Posner et al., '82; Shimizu and Kawashima, '89) and also with the observed effects of other embryotoxicants which disrupt lysosomal function in the VYS (Freeman and Lloyd, '83b; Daston et al., '90; Hunter et al., '91). These and other previous reports show that one of the primary effects of embryotoxicants which disrupt VYS histiotrophic nutrition is general growth retardation in the embryo proper, which is also consistent with the data presented here.

Regarding craniofacial morphology, histologic findings revealed that the lateral protrusions apparent in the cranial region of treated embryos were caused by aggregrations of abnormal cells underlying these areas. These particular cells correspond to cranial neural crest derivatives (primordia of the fifth cranial nerve) seen in the same region of control embryos. Rounded cell morphology and decreased extracellular space observed in histologic sections from $\mathrm{CQ}$-treated embryos leads to the speculation that disruption of cell-extracellular matrix interaction might play a role in CQ-induced dysmorphogenesis, since such interaction is an important determinant of neural crest morphology and motility in vitro (Tucker et al., '88; Perris et al., '91; Rogers et al., '92). Alterations in cranial neural crest cell migration (which occurs in the rat during GD 9-11) may affect craniofacial development since many of the craniofacial tissues are derived from this pluripotent cell population (Tan and Morriss-Kay, '89; reviewed in Noden, '88 and Le Dourian, '83). Further experiments are needed in order to investigate this possibility.

Whether CQ itself directly affects neural crest cell migration or differentiation, or whether these changes are a result of the more indirect effects of CQ on VYS function is uncertain. Close examination of the affected cells show that they are vacuoleladen and characteristic of CQ-exposed cells in other systems (de Duve et al., '74; Krogstad and Schlesinger, '86). This suggests a possible direct effect of CQ on the embryo proper, in addition to VYS effects.

The media CQ concentrations used in this study are an order of magnitude higher than those reached in the serum of patients receiving CQ therapy for rheumatologic disease (Mackenzie, ' 83 ). We cannot yet assess the relative sensitivities of rats and humans to CQ embryotoxicity and can only speculate that acute overdoses or cumulative effects of long-term low dose exposure to $C Q$ during pregnancy may also have adverse effects on human embryonic development. The possible direct effects of CQ on embry- 
onic cells, specifically the neural crest, suggest that both direct embryonic and indirect VYS effects may be involved in CQ embryotoxicity.

\section{ACKNOWLEDGMENTS}

The authors wish to thank Kaye Brabec, Lorita Dudis, and Dr. Kent Christensen for their assistance in preparing histological specimens. Thanks also to Sara Carlson, Roongrudee Hiranruengchok, and Bjorn Thorsrud for technical assistance and Dr. Tamara L. McNutt for help in editing the manuscript. This work was supported by NIH grants ES 05235, ES 07062, and HD 18258 and by the March of Dimes Birth Defects Foundation grant 15-179.

\section{LITERATURE CITED}

Basu, S.K., J.L. Goldstein, R.G.W. Anderson, and M.S Brown (1981) Monensin interrupts the recycling of low density lipoprotein receptors in human fibroblasts. Cell, 24:493-502.

Blazar, B.R., C.B. Whitley, A.E. Kitabchi, M.Y. Tsai, J Santiago, N. White, F.B. Stentz, and D.M. Brown (1984) In vivo chloroquine-induced inhibition of insulin degradation in a diabetic patient with severe in sulin resistance. Diabetes, 33:1133-1137.

Bradford, M.M. (1976) A rapid and sensitive method for quantitation of microgram quantities of protein using the principal of protein-dye binding. Anal. Biochem., $102: 344-352$.

Beck, F., J.B. Lloyd, and A. Griffiths (1967) Lysosomal enzyme inhibition by trypan blue: A theory of teratogenesis. Science, 157:1180-1182.

Beckman, D.A., T.R. Koszalka, M.M. Jensen, and R.L. Brent (1990) Experimental manipulation of the rodent visceral yolk sac. Teratology, 41:395-404.

Brent, R.L., D.A. Beckman, M. Jensen, and T.R. Koszalka (1990) Experimental yolk sac dysfunction as a model for studying nutritional disturbances in the embryo during early organogenesis. Teratology, 41 405-413.

Briggs, G.G., R.K. Freeman, and S.J. Yaffe (1990) A Reference Guide to Fetal and Neonatal Risk: Drugs in pregnancy and lactation. Williams \& Wilkins, Balti more, Md., pp. 112c-113c.

Burkard, W., and H. Fritz-Niggli (1987) Antiteratogenic and anticarcinogenic effects of $x$-rays in urethanetreated NMRI mice. Int. J. Radiat. Biol., 51:10311039.

Daston, G.P., D. Baines, J.E. Yonker, and L.D. LehmanMcKeeman (1991) Effects of lysosomal enzyme inhibition on the development of the rat embryo in vitro. Teratology, 43:253-261.

de Duve, C., T. de Barsy, B. Poole, A. Trouet, P. Tulkens, and F. Van Hoof (1974) Lysosomotropic agents. Biochem. Pharmacol., 23:2495-2531.

Essien, E.E., and G.C. Afamefuna (1982) Chloroquine and its metabolites in human cord blood, neonatal blood, and urine after maternal medication. Clin. Chem., 28(5):1148-1152.

Freeman, S.J. (1990) Functions of the extraembryonic membranes. In: Postimplantation Mammalian Embryos: A Practical Approach. A.J. Copp and D.L. Cock- roft, eds. Oxford University Press, New York, pp. $249-263$.

Freeman, S.J., F. Beck, and J.B. Lloyd (1981) The role of the visceral yolk sac in mediating protein utilization by rat embryos cultured in vitro. J. Embryol. Exp. Morphol., 66:223-234.

Freeman, S.J., and J.B. Lloyd (1983a) Evidence that protein ingested by the rat visceral yolk sac yields amino acids for synthesis of embryonic protein. J. Embryol. Exp. Morphol., 73:307-315

Freeman, S.J., and J.B. Lloyd (1983b) Inhibition of proteolysis in rat yolk sac as a cause of teratogenesis. Effects of leupeptin in vitro and in vivo. J. Embryol. Exp. Morphol., 78:183-193.

Gonzalez-Noriega, A., J.H. Grubb, V. Talkad, and W.S Sly (1980) Chloroquine inhibits lysosomal enzyme pinocytosis and enhances lysosomal enzyme secretion by impairing receptor recycling. J. Cell Biol., 85:839852.

Hart, C.W., and R.F. Naunton (1964) The ototoxicity of chloroquine phosphate. Arch. Otolaryngol., 80:407412.

Hunter, E.S. III, L.S. Phillips, S. Goldstein, and T.W Sadler (1991) Altered visceral yolk sac function produced by a low-molecular-weight somatomedin inhibitor. Teratology, 43:331-340.

Kaiser, N., A. Tur-Sinai, M. Hasin, and E. Cerasi (1985) Binding, degradation, and biological activity of insulin in vascular smooth muscle cells. Am. J. Physiol., 249:E292-E298.

King, A.C., L. Hernaez-Davis, and P. Cuatrecasas (1980) Lysomotropic amines cause intracellular accumulation of receptors for epidermal growth factor. Proc. Natl. Acad. Sci. USA, 77:3283-3287.

Krogstad, D.J., and P.H. Sehlesinger (1986) A perspective on antimalarial action: Effects of weak bases on Plasmodium falciparum. Biochem. Pharmacol., 35: $547-552$.

Labarca, L., and K. Paigen (1980) A simple rapid and sensitive DNA assay procedure. Anal. Biochem., 102 . 344-352.

Landauer, W. (1978) Cholinomimetic teratogens. VI The interaction of cholinomimetic teratogens with the antimalarial drugs chloroquine and chlorguanide. Teratology, 17:335-340.

Le Dourian, N.M. (1983) The Neural Crest. Cambridge University Press, Cambridge.

Levy, M., D. Buskila, D.D. Gladman, M.B. Urowitz, and G. Koren (1991) Pregnancy outcome following first trimester exposure to chloroquine. Am. J. Perinatol., $8: 174-178$

Lie, S.O., and B. Schofield (1973) Inactivation of lysosomal function in normal cultured human fibroblasts by chloroquine. Biochem. Pharmacol., 22:3109-3114.

Libby, P., S. Bursztajn, and A.L. Goldberg (1980) Degradation of the acetylcholine receptor in cultured muscle cells: Selective inhibitors and the fate of undegraded receptors. Cell, 19:481-491.

Livesey, G., K.E. Williams, S.E. Knowles, and J. Ballard (1980) Effects of weak bases on the degradation of endogenous and exogenous proteins by rat yolk sacs. Biochem. J., 188:895-903.

Lloyd, J.B. (1990) Cell physiology of the rat visceral yolk sac: A study of pinocytosis and lysosome function. Teratology, 41:383-395.

Mackenzie, A.H. (1983) Pharmacologic actions of 4-aminoquinoline compounds. Am. J. Med., $75(/ \alpha): 5-10$.

Mellman, I., R. Fuchs, and A. Helenius (1986) Acidification of the endocytic and exocytic pathways. Annu. Rev. Biochem., 55:663-700.

Merion, M., and W.S. Sly (1983) The role of intermedi- 
ate vesicles in the adsorptive endocytosis and transport of ligand to lysosomes by human fibroblasts. J. Cell Biol., 96:644-650.

Nato, F., M. Aubery and R. Bourrillon (1982) Approach to the mechanism of Zajdela's hepatoma cell growth inhibition induced by concanavalin $A$ and phytohaemagglutinin. Biochim. Biophys. Acta, 718:11-20.

Noden, D.M. (1988) Interactions and fates of avian craniofacial mesenchyme. Development (Suppl.) 103: 121-140.

Octave, J.-N., Y.J. Schneider, P. Hoffmann, A. Trouet, and R.R. Crichton (1982) Transferrin uptake by cultured rat embryo fibroblasts. The influence of lysosomotropic agents, iron chelators and colchicine on the uptake of iron and transferrin. Eur. J. Biochem., 123. $235-240$.

Ohkuma, S., and B. Poole (1978) Fluorescence probe measurements of the intralysosomal $\mathrm{pH}$ in living cells and the perturbation of $\mathrm{pH}$ by various agents. Proc. Nat. Acad. Sci. U.S.A., 75:3327-3331.

Perris, R., D. Krotoski and M. Bronner-Fraser (1991) Collagens in avain neural crest development: Distribution in vivo and migration-promoting ability in vitro. Development, 113:969-984.

Posner, B.I., B.A. Patel, M.N. Khan, and J.J.M. Bergeron (1982) Effect of chloroquine on the internalization of ${ }^{125}$ I-insulin into subcellular fractions of rat liver, J. Biol, Chem., 257:5789-5799.

Rogers, S.L., P.J. Gegick, S.M. Alexander, and P.G. McGuire (1992) Transforming growth factor- $\beta$ alters differentiation in cultures of avian neural crest-derived cells: Effects on cell morphology, proliferation, fibronectin expression, and melanogenesis. Dev. Biol., 151:192-203.

Seegmiller, R.E., C. Harris, D.L. Luchtel, and M.R Juchau (1991) Morphological differences elicited by two weak acids, retanoic and valproic, in rat embryos grown in vitro. Teratology, 43:133-150.

Sharma, A., and A.K. Rawat (1989) Toxicological consequences of chloroquine and ethanol on the developing fetus. Pharmacol. Biochem. Behav., 34:77-82.

Shimizu, A., and S. Kawashima (1989) Kinetic study of internalization and degradation of ${ }^{131} \mathrm{I}$-labeled folli- cle-stimulating hormone in mouse sertoli cells and its relevance to other systems, J. Biol. Chem., 264: 13632-13638.

Stark, K.L., C. Harris, and M.R. Juchau (1987) Embryotoxicity elicited by inhibition of $y$ glutamyltransferase by acivicin and transferase antibodies in cultured rat embryos. Toxicol. Appl. Pharmacol., 97:548-560.

Tan, S.S., and G.M. Morriss-Kay (1986) Analysis of cranial neural crest migration and early fates in postimplantation rat chimaeras. J. Embryol. Exp. Morphol., 98:21-58.

Tietze, C., P. Schlesinger, and P. Stahl (1980) Chloroquine and ammonium ion inhibit receptor-mediated endocytosis of mannose-glycoconjugates by macrophages: Apparent inhibition of receptor recycling Biochem. Biophys. Res. Commun., 93:1-8.

Tucker, G.C., J. Duband, S. Dufour, and J.P. Thiery (1988) Cell-adhesion and substrate-adhesion molecules: Their instructive roles in neural crest cell migration. Development (Suppl) 103:82-94.

Udalova, L.D. (1967) Effect of khingamin (chloroquine diphosphate, aralen) on the embryonal development in rats. Russ. Pharmacol. Toxicol,, 30:114-117.

Ullberg, S., N.G. Lindquist, and S.E. Sjostrand (1970) Accumulation of chorioretinotoxic drugs in the foetal eye. Nature, 227:1257-1258.

Wall, D., and T. Maack (1985) Endocytic uptake, transport, and catabolism of proteins by epithelial cells Am. J. Physiol., 248:C12-C20.

Wibo, M. and B. Poole (1974) Protein degradation in cultured cells. II. The uptake of chloroquine by rat fibroblasts and the inhibition of cellular protein degradation and cathepsin B1. J. Cell Biol., 63:430-440.

Wilson, J.G. (1973) Environment and Birth Defects. Academic Press, New York, p. 19.

Wolfe, M.S., and J.F. Cordero (1985) Safety of chloroquine in chemosuppression of malaria during preg nancy. Br. Med. J., 290:1466-1467.

Yielding, L.W., T.L. Riley, and K.L. Yielding (1976) Preliminary study of caffeine and chloroquine enhancement of $x$-ray induced birth defects. Biochem Biophys. Res. Commun., 68:1356-1361. 